\title{
Live and Dead Issues in the Methodology of Economics
}

\author{
David Colander \\ Middlebury College
}

\author{
Richard P.F. Holt \\ Southern Oregon University
}

J. Barkley Rosser, Jr.

James Madison University

May, 2007

\begin{abstract}
Responding to David Dequech's article (200X), we clarify our distinctions between the concepts of orthodox, mainstream, and heterodox economics. We agree that Dequech has pinpointed some areas where we have not been as clear as we might have been, but we suggest that in considering the fine points of the definitions, he has missed our broader message to heterodox economists, so we try to state our message a bit more explicitly.
\end{abstract}




\section{Live and Dead Issues In Methodology}

\section{Introduction}

In thinking about the issues raised in the paper, "Neoclassical, Mainstream, Orthodox, and Heterodox Economics” (Dequech, 200X), we were reminded of a 1938 article by Lionel Robbins entitled "Live and Dead Issues in the Methodology of Economics.” In it, Robbins apologized for stating certain propositions that he believed were obvious, such as "the object of economics is to understand reality," and argued that the difference between his definition and other definitions then current was not a very serious matter (Robbins, 1938, p. 344).

The reason we were reminded of this article is because it is our sense that many of the divisions we made in our Changing Face of Mainstream Economics (Colander et al, 2004a) were obvious, but too little remarked upon by most economists. ${ }^{1}$ We did not feel we were breaking new ground, but were instead summarizing changes that were taking place in the profession that we felt should affect the debate between heterodox economists, but were not. It was our sense that too many heterodox economists were fighting battles against a neoclassical enemy that the best of the mainstream did not believe existed, and that that fight marginalized heterodox economists in these mainstream economists’ eyes, and made it almost impossible for these heterodox economists to convey their ideas to mainstream economists.

We see ourselves as supporters of heterodox ideas as important and as worth considering. As supporters of heterodoxy, we have defended heterodox ideas to

\footnotetext{
${ }^{1}$ This article served as the foundation for interviews with a series of cutting edge economists who straddled the line between mainstream and heterodoxy in Colander et al (2004b). Others besides Dequech commenting specifically on our arguments have included Hodgson (2005), Davis (2006), Garnett (2006), Koppl (2006), and Lawson (2006).
} 


\section{Live and Dead Issues In Methodology}

mainstream economists, arguing that they should appreciate and recognize the contribution that heterodox economists have made, with little success. Our goal with that article was to convey to heterodox economists our sense of how ideas play out in the mainstream and the way in which categorization terminology is used. We wanted to reinforce the view, presented in Colander (2003) that fighting neoclassical economics is not a productive use of heterodox economist's time. It is a dead methodological issue.

We felt that picturing the economics profession as a complex adaptive system, in which new ideas were continually competing with old, provided a much better picture of the profession than did the static picture that existed in most heterodox and mainstream economists’ minds. In explaining our position we found it necessary to distinguish various groups of economists_-putting a static image on a continually moving picturebut we did not want to, and still do not want to, make too much of any particular division. The divisions we made are loose and arbitrary, and we could have chosen five or six different variations of those definitions, all of which would have conveyed the same ideas. But, we argue, precisely because the economics profession is a complex adaptive system, these groups should not be defined too carefully; they are continually changing as some ideas win out, and others lose. Precisely how the divisions are defined is not important to our central argument that the economics profession is a complex adaptive system, and of how, we believe, one can most usefully understand the profession, and advance one’s arguments within the profession. With that background, let us consider our agreements and disagreements with Dequech. 


\section{Agreements and Disagreements with Dequech}

We see Dequech as a friendly critic who wants to clear up our categories and amend them slightly. One area where he succeeds in pinpointing a certain ongoing ambivalence and evolution of thought on our part involves the role of the elite within the mainstream, even though we feel that he overstates the differences between his and our views of the sociological aspects of the mainstream. ${ }^{2}$ In our work, we defined the mainstream charitably — arguing that it should be defined by the best of the mainstream, which is often embodied in the profession's elite. We agree that such a definition places the mainstream in the best possible light, and misses the mindless focus on rankings rather than content and ideas in judging the value of research an of economists that can become effectively repressive. An example of such a mindless focus on ranking was what happened at Notre Dame, where the economics graduate program was separated from the heterodox economists even though the work that heterodox economists were doing was more closely aligned with the mission statement of that Catholic university, and even though the heterodox program was supported by leading mainstream economists such as Robert Solow (McCloskey, 2003). But, we argue, the best of the mainstream knows this narrow-mindedness for what it is, and agrees with heterodox economists that many in the mainstream are not as open-minded as they should be, just as the best of the heterodox knows that many heterodox economists are not as open-minded as they should be.

\footnotetext{
${ }^{2}$ In particular he emphasizes the importance of the mainstream having power. We agree that this is an important aspect of what it means to be in the mainstream.
} 
Our intention was that our definition would encourage heterodox economists to direct their arguments at the best of the mainstream because they are the ones who are most open to heterodox ideas. This point was perhaps most sharply made in our interview with Kenneth Arrow (Colander et al, 2004b, p. 298) where he discusses the case of heterodox economist, Samuel Bowles, being turned down for tenure at Harvard in the 1970s. He points out that the three former presidents of the AEA and the Nobel Prize winners involved in the decision all supported Bowles. ${ }^{3}$

We agree that one could define the categories differently; for example, we could have identified a mainstream orthodoxy. One reason we resisted specifically categorizing such a group was precisely because we were trying to highlight the non-orthodox nature of the elite and cutting edge portions of the sociologically mainstream. We do not deny that a portion of the mainstream would adhere to the intellectual apparatus of what might be called orthodoxy, but we do deny that this "orthodox" group controls the cutting edge of research, and that the mainstream can reasonably be defined by this narrow orthodoxy. $^{4}$

\footnotetext{
${ }^{3}$ This raises the curious point that even someone who looks like part of the elite from the outside may not feel like it from the inside and may maintain an alienated heterodox stance. This would appear to hold for several Nobel Prize winners even after they received these presumably highest marks of approval by the profession, with Herbert Simon apparently being one as reported by his student, Robert Axtell, in his interview with us (Colander et al, 2004b, p. 253). At Carnegie Mellon, Simon worked mostly in the psychology and computer science departments, avoiding the Graduate School of Industrial Administration because it was "being taken over by economists." In contrast, in his interview with us (Colander et al, 2004b, p. 103), Herbert Gintis recognized that he is widely viewed as being heterodox, but declared that "I don't like to be thought of as heterodox...I'm just a traditional scientist," and has in more than one setting verbally declared himself to be "homodox."

${ }^{4}$ In this regard there may be a disjuncture developing between microeconomics and macroeconomics. Many of the developments that we document involve microeconomics, where there has been a tremendous weakening of the previous orthodoxy in many ways. However, it could be argued that this older micro orthodoxy has had a revival in the apparent emergence of the newly orthodox version of macroeconomics based upon parts of it, the dynamic stochastic general equilibrium model (see Colander, 2006 for a critique).
} 


\section{Live and Dead Issues In Methodology}

For us, orthodoxy constitutes an ossification of what was formerly the cutting

edge. Its existence as a coherent intellectual whole is generally most strongly expressed in textbooks at the upper undergraduate and at the graduate levels, depending on the subfield of economics. In a complex adaptive system, as we think the economics profession is, the areas of research interest are continually changing, and those who adhere to orthodoxy are not those who are at the cutting edge. The genuinely creative and innovative researchers are continually looking to overturn any orthodoxy that develops. That is why we downplayed the "neoclassical" categorization.

Another area where we differ from Dequech is in his acceptance of Lawson's (2003) ontological specification of the divide between heterodoxy and mainstream, ${ }^{5}$ with heterodox approaches concentrating on open systems and the mainstream concentrating on closed systems, a view supported by Dow (1999), Moore (2006), and Davidson (1996). ${ }^{6}$ We agree that the economy is best seen as an open system, and that the mainstream has tended to concentrate on closed systems. But we believe that the reason for that is that they did not have the tools to analyze open systems, not that they did not believe the economic system was open. ${ }^{7}$ Thus, the assumption of a closed system is not a defining element of the mainstream.

\footnotetext{
${ }^{5}$ We note that Lawson identifies mainstream with orthodoxy. Lawson (2006) also identifies mainstream with mathematization, especially of a Bourbakist or "formalistic-deductivist" approach, a point Dequech also agrees with. We disagree, noting Weintraub’s (2002) discussion of Bourbakist formalism reaching a peak in mathematics in mid-20 ${ }^{\text {th }}$ century; with other more applied approaches now more important (Rosser, 2003). Thus such heterodox economists as the Marxists, Duménil and Lévy (2003), use mathematical methods that are not Bourbakist-formalist.

${ }^{6}$ Davidson (1996) has argued that Keynesian uncertainty is ontological, although he has tied this to an axiomatic view rather than the concept of openness of a system.

${ }^{7}$ Rosser (2006) has argued that complexity is an ontological foundation of Keynesian uncertainty, and that it is not necessarily tied to a system being open versus closed. It is an essential feature of complex Post Keynesian dynamics that they are endogenously generated by the system rather than arriving exogenously from outside the system as in the New Classical and DSGE approaches. Indeed, Rosser (2006) has argued
} 
In our view the mainstream has not given appropriate credit to Post Keynesians for their insights into the openness of the economy as is demonstrated by the standard mainstream histories of macroeconomics such as Blanchard (2000) or Woodford (2000) failing to mention Post Keynesians. In our discussions of the evolution of macroeconomic thought (Colander and Landreth, 1996; Colander, 2006; Rosser, 2006) we have argued that macro can only be thought of within a complex system framework, and that Post Keynesians are the one group that has consistently done so. ${ }^{8}$

\section{Our Broader Message}

We recognize that our views may have come across as anti-heterodox. Let us say specifically that that was not our intent. Two of us think of ourselves first as heterodox economists, and the third is highly sympathetic to heterodox ideas of all persuasions. ${ }^{9}$ The economics profession would be far better off if it took heterodox ideas more seriously, and our interest in shaking up heterodoxy is grounded in our belief that what they have to say is important and should be considered by the mainstream. Our concern is that heterodox ideas are not getting the hearing they should. We believe that the

at length that Post Keynesian models from the 1930s to 1950s served crucial roles in the formation of the understanding of complex dynamics by many modern economists.

${ }^{8}$ We note however that Davidson (1996) has rejected complexity as a foundation for uncertainty as being merely epistemological. Davidson effectively argues that complexity is not fundamentally a Keynesian concept, a view we disagree with (Colander, 1998; Rosser, 1998, 2006). Ironically, Blume and Durlauf (2006, p. 2) argue that complex models may not "represent a rejection of neoclassical economics," that it has been able to absorb these approaches, and view that both Rosser (forthcoming) and Colander (forthcoming) dispute.

${ }^{9}$ The ideas in our paper and book originated in discussions on the PKT-net and at a Post Keynesian seminar, and we all believe that heterodox economists have made, and continue to make, important contributions that the profession does not recognize The question of who is a what among us was discussed with some irony in the Preface to our book (2004b, p. viii) where it was noted that "Dave told Barkley that Barkley was no heterodox economist, as he had always pictured himself, but instead just another mainstream economist.” Barkley still likes to think of himself as heterodox, and in many ways he is very heterodox, but by our definition, because his work is taken seriously by the mainstream, and the approach he takes is seen by the mainstream as legitimate, he is not heterdox, but mainstream. 


\section{Live and Dead Issues In Methodology}

mainstream should recognize heterodoxy’s importance that goes beyond ideology (see Holt and Pressman, 1998). The profession needs people to tell it that there is a better way to do economics, and a better way to be an economist. It is what keeps the profession honest.

Pluralism does not come easy to any in power, and calls for pluralism inevitably come from the marginalized, which is what heterodox economists have become. If you believe in the correctness of your ideas, you don't want pluralism; you want your ideas to win out because they are correct. The best one can hope for in terms of pluralism is a level playing field so that ideas can compete. That level playing field can only be achieved if everyone knows the pitch one is playing on. That's what we tried to do in our article-convey to people the pitch, in the hope of making a more effective heterodoxy.

We argued in our Changing Face of Mainstream Economics that change in economics was unlikely to come through a Kuhnian paradigm shift that replaced a neoclassical orthodoxy with a heterodox alternative. Instead, the change would come from within, and it is already ongoing. If heterodox economics wants to affect that change, it must deal with that reality, and see that its ideas get a hearing at the edge of economics where the new ideas are sprouting.

Just as the mainstream is a complex adaptive system, so too is heterodoxy. It is constantly changing and has many different dimensions to it. Most heterodoxy today has developed in a way so it exists in a different niche than the mainstream. We have no problem with that, and perhaps one of these groups will grow sufficiently so that it can become the new mainstream. However, we see that as highly unlikely. Instead, we see it 


\section{Live and Dead Issues In Methodology}

as likely that each successive generation of these "outside the mainstream heterodox economists,” will become more and more marginalized. We wrote the paper because we believe that there is a different way - that there can and should be many more "inside the mainstream heterodox economists" than there currently are. "Inside the mainstream heterodox economists” are much harder to marginalize. Our article and book were designed to influence the internal dynamics of heterodoxy, and to change how young heterodox economists see their role. Our goal was to encourage the development of young heterodox economists whom the mainstream will find harder to marginalize, and our book was essentially some implicit advice for young heterodox economists. That advice was probably a bit too implicit, so let us state it a bit more explicitly.

If a heterodox economist wants to be listened to by the mainstream, some rules she or he should follow are:

- Don't worry about methodology. Unless you are a philosopher specializing in methodology, just about everything to be said about methodology has been said. To think that anyone but a specialist is going to have much to add on methodology is similar to a neophyte thinking he can do better than an index fund in investing. Only long-in tooth, (or almost long-in tooth) economists such as us are given a pass to write on methodology. But even for this group, such writings are not highly valued as research output, and are considered a diversion from doing real economics, on a par with golf, although golf probably gets slightly higher value. 
- Do not worry about divisions within economics; we are all economists. There are many dimensions of economics, and depending on the dimension that is being emphasized one will come up with different divisions. The three of us are mainstream, orthodox, and heterodox economists simultaneously, as we believe the majority of economists are. That multidimensionality means that dividing economists up into such groupings is not a fruitful exercise-economists are economists, and at any one time some ideas are winning out and others not. To differentiate out a group of economists as heterodox frees them to not deal with the fact that their ideas are not winning out, and to place the blame for it on the rigidity of the mainstream orthodoxy. We agree there is such rigidity, but we also believe that that rigidity is simply reflective of the rigidity of power of any group in power, and something that heterodox economists are going to have to live with.

- Be preparing your ideas to leave the incubator. Our goal in writing our book and paper was to encourage heterodox economists to get into the mainstream conversation - to argue that it is not the ideas that one has that are held out, but rather the method one uses to present them. Ideas compete in an institutional environment (controlled by the mainstream) and if ideas are to win out, they have to compete in that mainstream institutional environment. Heterodox environments are like incubators for ideas, and often heterodox ideas grow nicely in that incubator. But at some point, the ideas must be taken from the incubator and left to play in the mainstream institutional environment if they are to influence the mainstream. It was to encourage heterodox economists to leave the incubator that we chose our definition of mainstream and orthodoxy, giving wide latitude to 


\section{Live and Dead Issues In Methodology}

mainstream, and emphasizing the ideas on the cutting edge as the ideas in play.

We fully agree that the textbook presentations are believed by some economists, and that these textbook ideas are in the mainstream pedagogy. But if anyone were to actually try to publish a paper based on these, or use them directly in their research, they would be out of the mainstream. It is just not part of the research journal discussion. Criticizing textbook ideas as a description of what the mainstream believes is not a productive endeavor. The comparative advantage heterodoxy has over the orthodoxy is its willingness to constantly question ideas and foundations of economics. Often, the mainstream, in its focus on narrow issues, loses sight of these foundations, and thus need to be reminded of them. The best or the elite in the mainstream encourage this questioning as long as it is done with what the mainstream believes is a deep understanding of what those foundational questions are. So our argument was that if one is to criticize and have that criticism considered by the mainstream, criticize the best of the mainstream, and do it with a deep understanding what they believe; don't criticize a straw man to be found in the textbook. That suggestion holds no matter what specific definition of the terms one chooses.

- Think of yourself as an economist first, and as a heterodox economist second. The last suggestion for heterodox economists that we suggest is to think of yourself primarily as an economist rather than as a heterodox economist. Doing so will lead to less thinking about methodology, and more thinking about substantive issues. In our view, doing so will make both those who consider themselves mainstream and those who consider themselves heterodox better off. 


\section{References}

Blume, L.E. and Durlauf, S.N. “Introduction.” In Blume, L.E. and Durlauf, S.N. (eds.), The Economy as an Evolving Complex System III: Current Perspectives and Future Directions. Oxford: Oxford University Press, 2006, pp. 1-4.

Blanchard, O. "What Do We Know about Macroeconomics that Fisher and Wicksell Did Not? Quarterly Journal of Economics, November 2000, 115(4), 1375-1410.

Colander, D. “Beyond New Keynesian Economics: Post Walrasian Economics.” In Rotheim, R. (ed.), New Keynesian Economics Post Keynesian Alternatives. London: Routledge, 1998, pp. 277-287.

Colander, D. “The Death of Neoclassical Economics.” Journal of the History of Economic Thought, June 2000, 22(2), 127-143.

Colander, D. "Post Walrasian Macroeconomics and Heterodoxy: Thinking Outside the Heterodox Box.” International Journal of Political Economy, Summer 2003, 33(2), 68-81.

Colander, D. (ed.) Post Walrasian Macroeconomics: Beyond the Dynamic Stochastic General Equilibrium Model. New York: Cambridge University Press, 2006.

Colander, D. "Review of The Economy as a Evolving Complex System III" Economica, forthcoming.

Colander, D. and Harry Landreth, The Coming of Keynesianism to America: Conversations with the Founders of Keynesian Economics. Chelthenham: Edward Elgar 1996.

Colander, D., Holt, R.P.F. Holt, and Rosser, J.B., Jr. “The Changing Face of Mainstream Economics.” Review of Political Economy, 2004a, 16(4), 485-499.

Colander, D., Holt, R.P.F., and Rosser, J.B., Jr. The Changing Face of Economics: Conversations with Cutting Edge Economists. Ann Arbor: University of Michigan Press, 2004b.

Davidson, P. “Reality and Economic Theory.” Journal of Post Keynesian Economics, Summer 1996, 18(4), 479-508.

Davis, J.B. “The Turn in Economics: Neoclassical Dominance to Mainstream Pluralism?” Journal of Institutional Economics, April 2006, 2(1), 1-20.

Dequech, D. “Neoclassical, Orthodox, Mainstream, and Heterodox Economics” Journal of Post Keynesian Economics, this issue. 
Dow, S.C. "Post Keynesianism and Critical Realism: What is the Connection?” Journal of Post Keynesian Economics, Fall 1999, 22(1), 15-33.

Duménil, G. and Lévy, D. “Technology and Distribution: Historical Trajectories a la Marx.” Journal of Economic Behavior and Organization, October 2003, 52(2), 201233.

Garnett, R.F., Jr. “Paradigms and Pluralism in Heterodox Economics.” Review of Political Economy, 2006, 18(4), 521-546.

Hodgson, G.M. “Characterizing Institutional and Heterodox Economics - A Reply to Tony Lawson.” Evolutionary and Institutional Economics, 2005, 2(2), 213-223.

Holt, R.P.F. and Pressman, S. Economics and its Discontents: Twentieth Century Dissenting Economists. Cheltenham: Edward Elgar, 1998.

Koppl, R. “Austrian Economics at the Cutting Edge.” Review of Austrian Economics, 2006, 19(4), 231-241.

Lawson, T. Reorienting Economics. London: Routledge, 2003.

Lawson, T. “The Nature of Heterodox Economics.” Cambridge Journal of Economics, July 2006, 30(4), 483-505.

McCloskey, D.N. “Notre Dame Loses.” Eastern Economic Journal, Spring, 2003, 29(2), 309-315.

Moore, B.J. Shaking the Invisible Hand: Complexity, Endogenous Money and Exogenous Interest Rates. Basingstoke: Palgrave Macmillan, 2006.

Robbins, L. "Live and Dead Issues in the Methodology of Economics.” Economica, August 1938, 5, 342-352.

Rosser, J.B., Jr. “Complex Dynamics in New Keynesian and Post Keynesian Economics.” In Rotheim, R. New Keynesian Economics/Post Keynesian Alternatives. London: Routledge, pp. 288-302.

Rosser, J.B., Jr. “Weintraub on Mathematical Economics: A Review Essay.” Journal of Post Keynesian Economics, Summer 2003, 25(4), 575-589.

Rosser, J.B., Jr. “Complex Dynamics and Post Keynesian Economics.” In M. Setterfield (ed.), Complexity, Endogenous Money and Macroeconomic Theory: Essays in Honour of Basil J. Moore. Cheltenham: Edward Elgar, 2006, pp. 74-98.

Rosser, J.B., Jr. "Book Review of The Economy as a Complex Evolving System III: Current Perspectives and Future Directions.” Journal of Economic Behavior and Organization, forthcoming. 
Weintraub, E.R. How Economics Became a Mathematical Science. Durham: Duke University Press, 2002.

Woodford, M. "Revolution and Evolution in Twentieth-Century Macroeconomics," June 1999. Presented at a conference, Frontiers of the Mind in the Twenty-First Century, U.S. Library of Congress, Washington, D.C., June 1999. 